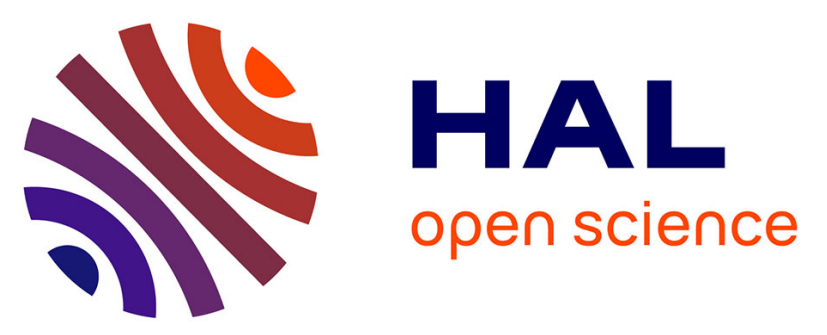

\title{
Analysis of How People with Intellectual Disabilities Organize Information Using Computerized Guidance
}

Dany Lussier-Desrochers, Hélène Sauzéon, Charles Consel, Jennie Roux, Emilie Balland, Valérie Godin-Tremblay, Bernard N'Kaoua, Yves Lachapelle

\section{- To cite this version:}

Dany Lussier-Desrochers, Hélène Sauzéon, Charles Consel, Jennie Roux, Emilie Balland, et al.. Analysis of How People with Intellectual Disabilities Organize Information Using Computerized Guidance. Disability and Rehabilitation: Assistive Technology, 2016, à paraitre, 10.3109/17483107.2015.1136000 . hal-01251888

\author{
HAL Id: hal-01251888 \\ https://hal.inria.fr/hal-01251888
}

Submitted on 28 May 2016

HAL is a multi-disciplinary open access archive for the deposit and dissemination of scientific research documents, whether they are published or not. The documents may come from teaching and research institutions in France or abroad, or from public or private research centers.
L'archive ouverte pluridisciplinaire HAL, est destinée au dépôt et à la diffusion de documents scientifiques de niveau recherche, publiés ou non, émanant des établissements d'enseignement et de recherche français ou étrangers, des laboratoires publics ou privés. 


\section{Title:}

Analysis of how people with intellectual disabilities

organize information using computerized

guidance

\section{Authors:}

\section{Dany Lussier-Desrochers (Corresponding author)}

Université du Québec à Trois-Rivières, Département de psychoéducation

Adresse: 3600, Rue Sainte Marguerite, Trois-Rivières, QC. Bureau 2048

No de telephone: $819376-5011$, poste 4087

Courriel: Dany.Lussier-Desrochers@uqtr.ca

\section{Hélène Sauzéon,}

Phoenix Team, Inria, Talence, France

EA4136-Laboratoire " Handicap et Système Nerveux", Université de Bordeaux, Bordeaux, France

Adresse: Bureau B 321 - INRIA Bordeaux-Sud Ouest 200, avenue de la Vieille Tour 33405 Talence

No de téléphone : +33(0)524574111

Courriel : helene.sauzeon@inria.fr

\section{Charles Consel}

Phoenix Team, Inria, Talence, France

Institut National Polytechnique de Bordeaux, Talence, France

University of Bordeaux / INRIA / LaBRI- Head of the Phoenix research group

Adresse: 351, cours de la Libération, Bat. A29

33405 Talence Cedex

No de téléphone: 33 (0)5 24574035

Courriel: Charles.Consel@inria.fr

Jeannie Roux

Conseillère technoclinique- crdited mcq - iu 3255, rue Foucher, Trois-Rivières, Québec, G8Z 1 M6

Téléphone : 819-376-3984, poste 395

Courriel: Jeannie_Roux_crditedmcqiu@ssss.gouv.qc.ca

\section{Émilie Balland}

Address : Bureau B321 - INRIA Bordeaux-Sud Ouest 200, avenue de la Vieille Tour 33405 Talence No de téléphone: +33(0)524574111

Courriel : emilie.balland@inria.fr

\section{Valérie Godin-Tremblay}

Université du Québec à Trois-Rivières, Département de psychoéducation

Adresse: 3600, Rue Sainte Marguerite, Trois-Rivières, QC. Bureau 2049

No de telephone: 819 376-5011, poste 4098

Courriel: Valerie.Godin-Tremblay@uqtr.ca

\section{Bernard N'Kaoua}


Phoenix Team, Inria, Talence, France

Service de Médecine Physique et Réadaptation - Hôpital Tastet Girard

CHU Pellegrin

Place Amélie Raba Léon, 33076 Bordeaux cedex, France

Tel : +33 (0)5 57820235

Courriel: bernard.nkaoua@u-bordeaux2.fr

Yves Lachapelle

Université du Québec à Trois-Rivières, Département de psychoéducation

Adresse: 3600, Rue Sainte Marguerite, Trois-Rivières, QC. Bureau 2044

No de telephone: 819 376-5011, poste 4009

Courriel: Yves.Lachapelle@uqtr.ca

\begin{abstract}
:
Access to residential settings for people with intellectual disabilities (ID) contributes to their social participation, but presents particular challenges. Assistive technologies can help people perform activities of daily living. However, the majority of the computerized solutions offered use guidance modes with a fixed, unchanging sequencing that leaves little room for self-determination to emerge. The objective of the project was to develop a flexible guidance mode and to test it with participants, to describe their information organization methods. This research used a descriptive exploratory design and conducted a comparison between five participants with ID and five participants with no ID. The results showed a difference in the information organization methods for both categories of participants. The people with ID used more diversified organization methods (categorical, schematic, action-directed) than the neurotypical participants (visual, action-directed). These organization methods varied depending on the people, but also on the characteristics of the requested task. Furthermore, several people with ID presented difficulties when switching from virtual to real mode. These results demonstrate the importance of developing flexible guidance modes adapted to the users' cognitive strategies, to maximize their benefits. Studies using experimental designs will have to be conducted to determine the impacts of more-flexible guidance modes.
\end{abstract}

Keywords: Cognitive strategies, flexible guidance mode

\title{
Implications for rehabilitation
}

- Intervention approaches favoring, self-determination, decision making, action analysis, and results anticipation must be promoted with people with intellectual disabilities

- Fixed and rigid technological guidance mode, like those currently favored in interventions, is appropriate for only some people's profiles or may depend on the nature of the task.

- It seems that people with ID use a wide spectrum of organization strategies and that adapting guidance modes to all these strategies is relevant. 


\section{Introduction}

Social participation and integration of people with intellectual disabilities (ID) is a priority in the fields of rehabilitation and social services. As such, support for residential integration of these people is currently a priority in Québec [1]. In fact, a residential setting represents 'an indicator of independence, self-reliance and normality' [2] and constitutes an important component of social participation $[3,4,5,6,7,8,9,10]$. Unfortunately, for people with ID, their significant limitations related to functional and adaptive competencies complicate the performance of some activities of daily living (ADLs) in a home setting. Preparing meals, maintaining a secure environment, taking medication, maintaining a residential environment, managing a budget, managing their time, hygiene, and health are areas where greater assistance is required $[2,11,12]$. Information and communication technologies (ICT) are among the means used to help these people perform ADLs in a residential setting. These means of assistance have been the subject of several studies in recent years. ICT are used notably as guidance devices for performing ADLs.

\section{Prompting to help perform ADLs}

Prompting is a type of stimuli that act as cues to help the person perform the expected behaviour [13]. Several prompting modalities are used to assist people with ID [14], including picture prompting systems, auditory prompting systems (MP3 players) and video prompting $[15$, $16,17,18,19]$. Audio and video systems may be presented on a variety of digital supports [17], such as touch-screen MP3 players [15, 16], personal digital assistants (PDAs), digital tablets, laptops, desktop computers [20, 21, 22] or portable video players [23]. In the past few years, prompting on digital tablets or on iPod touch has been gaining in popularity. In fact, these types of consumer technologies are less stigmatizing for people with ID [24]. 
Published studies pertaining specifically to the use of high-tech prompting to help perform ADLs generally address three broad types of tasks: household (e.g. cleaning furniture, using a vacuum cleaner, folding clothes) $[25,26,27,28,29 ; 30,31]$; preparing food and related tasks (e.g. putting away groceries, setting a table, washing dishes) [15, 28, 32, 33, 34]; activities in the community (using an ATM or travelling within the community) $[35,36]$; vocational tasks $[24,37,38,39]$; and time management $[40,41]$. The results obtained show that this intervention method promotes a higher rate of success in performing the proposed tasks $[24,27,28,29,32$, $41,42$,$] , reduces the amount of human assistance required to perform the task [24, 27, 30, 37],$ improves daily living skills [27, 43] and helps in learning new tasks [27, 44].

If we take a closer look at the use of prompting on high-tech and mobile assistive technologies (electronic tablets, iPods, PDAs, smart phones) to help people with ID perform ADLs, we see that several use a linear method of presenting the prompts $[5,7,8,15,24,28,29$, $30,31,35,36,38,39,40,45]$. Participants must thus perform the tasks in a specific, predetermined order. This modality helps to limit the number of methodological biases and to ensure a more accurate measure of dependent variables, such as the percentage of steps performed correctly, the average number of errors, the average number of cues given, the number of steps performed independently, etc. However, this type of prompting does not necessarily allow the development of all components relating to self-determination, which constitutes a central principle of intervention in the field of ID [46]. In fact, although the results of these studies show that this type of prompting is effective for supporting the learning of skills and the development of behavioural autonomy, it does not offer the possibility of addressing other self-determination dimensions (self-regulation, psychological empowerment and selfrealization). Indeed, several studies show that these prompting modalities leave little room for 
participants to express their preferences by making choices. Finally, the use of this type of guidance does not take into account inter-individual or inter-occasion variability in the information organization methods of people with ID.

Nonetheless, a few studies have evaluated the effects of more flexible prompting modalities that allow the person to make choices and decisions. For example, in some studies, the prompting device includes a decision point where the person must choose between several possible actions $[27,37,47]$. In some cases, the person can also omit or change the order of the proposed steps without this being counted as an error [27, 47]. This type of prompting thus helps to support choices or decision making. In the long term, non-linear prompting modalities would prevent people from losing their cognitive skills [48].

In summary, several prompting modalities are proposed and may be adapted to various contexts. That said, it appears that fixed prompting would be more suitable to objectives related to learning or developing new skills, while more flexible prompting would be more appropriate for objectives related to substituting or compensating for limitations in performing ADLs [49, 50]. These two modalities can therefore act in complementarity.

\section{Information organization methods of people with ID}

Several studies have shown that semantic knowledge is stored according to various organization methods that are more or less developed in terms of abstraction [51]. The organization mode using categorical reasoning is the most abstract. A person using this method will group, for example, the fork and knife in the 'cutlery' category. In the schematic organization mode, the information is organized according to a context or a situation. The information is thus grouped according to spatial or temporal relationships. For instance, the fork and knife would be temporally and spatially recurring in the 'setting the table' situation. Finally, pragmatic 
organization is directed rather by the functionalities of items. In this organization mode, the knife and fork would be grouped under the 'instruments used to feed yourself' category.

Regarding more specifically the information organization methods used by people with ID, studies reveal a great heterogeneity in the semantic organization profiles $[52,53]$. Consequently, some results show that these people are able to spontaneously classify the information categorically but exhibit a preference for schematic or functional organizations [53]. Some studies reveal also that one person may use various organization methods depending on the context or the type of information [54].

These elements clearly show that a guidance interface structured a priori using a specific method of information organization makes the cues more difficult to understand for people who do not possess the semantic connections that served as referents. Exclusion created by an environmental support unsuited to the person's knowledge could be circumvented by designing guidance technologies in which the content display is poorly organized, so as to allow the person to choose his or her preferred organization strategy, while being steered towards the sub-goals required to successfully perform the task.

\section{Research objective and questions}

The research objective was to analyse the interactions between users with ID and a computerized guidance interface with poorly organized content, to describe the information organization methods. The research also pursued a sub-objective aimed at making a comparison between the information organization methods of people with ID and those of people with no ID, matched according to age.

\section{Method}

The following subsections present the design, experiment location, materials used, 
sampling method, experimental process, and data analysis procedure.

\section{Design}

Given that this is a new field of research and that few studies on computerized guidance have addressed the theme from this angle, a descriptive exploratory research design was used. Therefore, the participants were immersed in two navigational experiments that were then examined in detail through maps describing the trajectories used.

\section{Experiment location and materials used}

The study was conducted at (removed to prevent identification). The laboratory was an accurate replica of a four-room, fully furnished apartment (living room, kitchen, bedroom and bathroom). To perform the required tasks, the participants used a guidance application (removed to prevent identification) installed on an iPad 2. This application, developed by (removed to prevent identification), was subdivided into two sections. The first asked the person to bring a certain number of foods and other items needed for a picnic, and the second asked the person to secure the research lab (i.e. smart apartment) before leaving (cf. laboratory description further down). The application consisted of images and written instructions for which an auditory aid could be activated by the user.

For the 'picnic' section, three items were selected for each of the four predetermined categories (i.e. food, cutlery, outdoor games, and personal-care items for the outdoors) [45]. This section of the application displayed two series of six disorganized items sequentially (e.g. no spatial contiguity between two items from a same category). These materials thus allowed the participants to use, at their convenience, categorical, schematic or functional relationships to perform this part of the task. For the 'securing' section, six securing actions had to be performed in the laboratory: turn off the stove, the kettle, the lights, the television and the clothes dryer, and 
close the faucets. The actions were all semantically connected to the notion of securing but differed according to the places where they were to be performed (i.e., divided among the four rooms in the laboratory). This section of the application was used to assess the participants' spontaneous ability to optimize their time by performing the actions room by room.

Each part ended with a summary of the elements gathered or secured. A maximum of six images were visible at one time (corresponding to the visual memory often preserved by people with ID) [55].

\section{Participants and sampling method}

The participants solicited were five people with a minor intellectual disability between 18 and 35 years of age. Two inclusion criteria were retained for selecting participants: be living in an apartment or intending to live in an autonomous residential setting as an intervention objective, and being able to use a computer. Two exclusion criteria were also retained: having a behavioural disorder and having a physical disability. To conduct comparative analyses, five participants with no ID were solicited and matched with the sample of five people with ID, based on the 'age' variable. This matching was a way to partially control the bias related to having been exposed to technologies and to thus limit the generational bias associated with the use of technologies.

An accidental, non-probabilistic sampling method was used. Participants with ID were recruited in collaboration with the (removed to prevent identification), a centre for intellectual disability and pervasive development disorder rehabilitation. Meanwhile, participants with no ID were solicited during one bachelor's-level class and one master's-level class at the (removed to prevent identification). In the end, five age categories were represented in the sample $(23,24,25$, 26 and 31 years). The research was approved by two research ethics committees (i.e. 
rehabilitation centre and university). All participants signed an informed consent form.

\section{Experimental process}

The experiment was conducted in three stages.

Stage 1. Technology introduction meeting. The first meeting was intended only for the people with ID, and the objective was to show them the basic functions of the iPad (turn on the device, open the application, click, navigate, slide), as well as how to operate the application (listen to the audio command, read the instruction, confirm the action). The introduction was made using a lighter version of the application. However, so as to not bias the participants' performance, items other than those used in the experiment were selected. At this stage, participants having difficulties could request help from the research assistant.

Stage 2. 'Bring items' experiment. During the second meeting, the participants with ID and those with no ID used SecurApp to bring the items needed for a picnic. The participant was positioned in a central location in the apartment (kitchen island) and was handed the iPad. During these steps, the 12 items described in the 'materials' section had to be gathered into a backpack.

Stage 3. 'Secure the environment' experiment. Stage 3 was conducted in the same manner as Stage 2. The assistant asked the participants with ID and those with no ID to use SecurApp to secure the apartment and leave the experiment site. The person was placed in the same spot (kitchen island) as for the previous experiment.

\section{Analyses}

All the navigation trajectories performed on the interface were recorded by a cookie installed on the electronic tablet. For each of the participants, a navigation map was drawn for each of the requested tasks (bring a meal for a picnic, bring items for a picnic and secure the 
apartment before leaving). These maps were then analysed to find the method used to organize the information, as well as the similarities and differences in these methods, by proposed task and by participant profile (ID versus no ID). All the experiments were filmed and each map was validated by viewing the video sequences.

\section{Results}

The analyses of the maps for all participants showed a greater variability in the information organization strategies used by the people with ID. Overall, these participants used four organization modes. The first was a visual one called 'literal reading', where the application was read like a written text, from left to right and from top to bottom. The second was a categorical organization mode, where the items were selected according to the categorical relationships that connect them. The third was a schematic organization mode, where the items were selected according to the situational/contextual relationships that connect them. The fourth was an action-directed organization mode, where the actions performed on the items to accomplish the task underway were carried out by spatial proximity. However, the analyses showed that none of the participants with ID systematically used only one organization mode for all the proposed tasks; variability was observed according to the nature of the task. Of the five participants with no ID, two systematically used the same organization mode for all the proposed tasks. Table 1 presents a summary of the information organization methods used by the participants with ID.

Insert table 1 about here

Before describing the participants' organization modes in more detail, further 
explanations are needed concerning the method used by the people with ID to perform the tasks. The analysis showed that several did not clearly understand the instruction and used only the application without performing the task in the environment; this was not the case for the participants with no ID. Therefore, several participants did not integrate the virtual (using the application) and real (performing the actions in the environment) dimensions of the task. Consequently, several people with ID remained in the virtual dimension and, therefore, did not accomplish the requested task in the intelligent apartment. However, several of them repeated the proposed task. The analysis of the video sequences suggested that these participants suspected that there was a second component to the task, but several were unable to clearly identify the expectations of the experimenter who, to avoid bias, had to conform to the proposed experimental protocol. Therefore, in Table 1, the organization modes between parentheses represent situations where the person used only the application, while those not between parentheses represent situations where the requested task was performed in the environment. We can thus see that some participants did not necessarily use the same mode when they switched over.

For the specific 'Bring a meal for a picnic' task, two participants with ID responded appropriately to the instruction and performed the action in both the application and the environment. Participant No. 5 used an 'action-directed' mode, performing behaviours that optimized his spatial position in the environment. He thus brought all the items from the fridge, and then gathered the ones from the counter. Meanwhile, Participant No. 3 performed the task first in the application and then in the environment. However, a specific information organization mode was not identified through the analysis of this participant's actions. Two participants (No. 1 and No. 7) used a 'categorical' strategy, where the items were grouped according to the 
relationships that connect them (utensils and food). This strategy indicates that they possessed and self-initiated abstract semantic knowledge to plan how to perform the requested task. However, none of these participants performed the task in the environment. Finally, Participant No. 9 used a schematic organization. The items were thus selected according to the schematic relationships that connect them (e.g. temporal usage relationships of items for a meal). The categorical and schematic modes refer to an information organization based on previously learned or used knowledge. Figure 1 presents the map for this participant and shows the precise order in which the task was performed.

Insert figure 1 about here

For the 'Bring items for a picnic' task, three participants with ID began by navigating randomly in the application without specifically using information organization modes. However, two of the three (No. 3 and No. 9) repeated the task in the application. This is the point where Participant No. 3 switched from virtual to real mode and from an unspecified organization mode to a visual mode similar to reading. We thus see that this participant read the application like a written text, from left to right and from top to bottom. This strategy reveals self-initiation of an overlearned habit of scanning and visually exploring a medium. The same phenomenon occurred with Participant No. 9, who switched from an unspecified organization mode to a visual mode but without actually performing the task (the person performed it only on the tablet).

For the 'Secure the apartment before leaving' task, only Participant No. 9 stayed in virtual mode, performing the task only in the application, using a visual organization mode similar to reading. Three other participants (No.1, No. 3 and No.7) also used this visual organization 
mode but performed the task simultaneously in the environment (integration of virtual and real). Only one participant with an intellectual disability (No. 5) used an action-directed strategy. Figure 2 presents the map of the fifth participant's actions.

Insert figure 2 about here

The analysis of the maps for the participants with no ID shows a greater homogeneity in the information organization methods notably with respect to the first two proposed tasks ('Bring a meal for a picnic' and 'Bring items required for a picnic'). Table 2 summarizes the results for this group of participants.

Insert table 2 about here

Participants with no ID systematically used the visual mode of information organization. This simple, self-initiated strategy is directed by the content of the medium and suggests the predominance of an overlearned reading strategy involving visual scanning among the participants with no ID. Nevertheless, during the securing task, three of the participants (No. 4, No. 6 and No. 10) changed their information organization method to an action-directed strategy, in which the participants' actions were guided by spatial proximity. The departure point of the initial action varied, however, from one person to the next, with some preferring to first close the faucets and others, to turn off the electric appliances (kettle).

\section{Discussion}

The objective of this research was to analyse how users with ID interact with a guidance 
interface that does not present a fixed sequence in which to perform a task and to make a comparison between their information organization methods and those of the participants with no ID. In practical terms, the research helped notably to map the navigation trajectories and to observe a greater variability in the organization modes used by the participants with ID. These participants used four methods: visual, categorical, schematic and action-directed. These results support those from studies mentioning the heterogeneity of the semantic-organization profiles $[52,53]$ and the conclusions of [54], underscoring the presence of various information organization methods among these people. However, this phenomenon may be explained by individual differences that could not be evaluated systematically due to the sample size. However, this situation had not yet been observed in the research on computerized guidance modes. This may be because, until now, fixed guidance modes had been generally used in studies among people with ID. These fixed modes leave little room for self-initiation of information organization strategies. The results of our research suggest rather that fixed guidance modes are better suited to people with no ID, who seem to 'read the application' and favour a visual strategy. This guidance method limits the activation of certain cognitive processes (memory, planning, problem-solving). For people with ID, it seems preferable to offer some flexibility to allow them to use personalized information organization modes that will help them perform the proposed tasks more successfully.

The analyses also revealed a particular phenomenon related to the 'secure the apartment' task. In fact, during this task, four of the five participants with ID adopted a visual mode similar to the one used mostly by the participants with no ID in other tasks. Conversely, the participants with no ID dropped this strategy for an action-directed one. In our opinion, two hypotheses might explain this situation. First, the nature of the task could account for this phenomenon. In 
fact, for this task, auditory and visual cues caught the participants' attention (sound of the faucet running, steam from the kettle) and then directed their actions in the environment. It thus seems that for people with no ID, these cues directed the sequence of their actions. Meanwhile, only one of the participants with ID responded to these environmental cues, and it was the steam from the kettle that caught his attention. For the other people with ID, these cues did not seem to help them prioritize the actions to be accomplished, and were elements of distraction. It thus seems that the people with ID disregarded this information and settled for a strategy similar to reading (visual). A second hypothesis can be linked to the sequence in which the three tasks were performed. It is possible that in a context of new elements, people with ID attempt to give a meaning to the task by using an organization method that helps them better understand what is presented to them. However, after several attempts, they would end up using a strategy similar to reading (visual). In both cases, this shows that they have difficulty making decisions when faced with new situations $[55,56]$ and turn to a simple reading strategy. Meanwhile, the participants with no ID would have started the task using over-learned, self-initiated strategies of visual scanning similar to reading. However, in the final task, they would have adapted their strategies, and several used the environmental cues to guide them.

In summary, the results show that people with ID process information cognitively when performing a task and that the guidance must take this element into account. It thus seems that a fixed, linear guidance mode, like those currently favoured in interventions, is appropriate for only some people's profiles or may depend on the nature of the task (learning perspective) [49, 50]. It also seems that people with ID use a wide spectrum of organization strategies and that adapting guidance modes to all these strategies is relevant. This will undoubtedly improve how well the tasks are performed, but will also promote intervention approaches favouring decision 
making, action analysis, and results anticipation, which will meet the requirements of self-determination intervention [57]. Of course, these elements are just avenues for reflection and will require further examination in other studies, to find out whether it is the nature of the task or its subsequent performance that influences the information organization method.

It should also be noted that several participants with ID were unable to switch from the virtual dimension to the real one. They were therefore unable to perform the requested task in the apartment. This situation did not present itself at all for the participants with no ID. The difficulty experienced by these people with ID in shifting from virtual to real mode could be likened to the well-known problem related to transferring rehabilitation strategies to daily living situations traditionally observed among patients with brain injuries and cognitive disorders [58, 59]. Furthermore, in studies using virtual reality as a medium for learning or relearning ADLs, this transfer problem was reduced but not eliminated [60]. Therefore, people with ID who do not make the virtual-real transfer may not perceive or understand the connection between the two situations or they could see the connection without performing the expected actions in the real situation. It would thus be relevant to examine this dimension in more detail, to better understand the cognitive processes involved in navigating in the applications and performing the tasks in the environment, and to see how the cognitive processes might act in complementarity or in duality.

Nonetheless, this research presents several limitations. First, the choice of a descriptive design allowed us to examine the organization methods but not specifically the impacts of these methods on other variables, such as the percentage of steps accomplished correctly, the average number of errors, the average number of cues transmitted, the number of steps performed independently, etc. These elements could be studied using experimental or quasi-experimental designs. Furthermore, the low number of participants and the non-probabilistic sampling method 
greatly limit the possibility of generalizing the study results. With respect to the experimental procedure, limitations were found regarding the instructions for the task. They need to be revised to give people a clearer idea of the expected behaviours.

\section{Conclusion}

The results of this first descriptive study have helped bring a new dimension to the reflection on the use of technological guidance modes supporting the performance of ADLs. They tend to demonstrate the importance of developing more flexible guidance modes and adapting them to the cognitive profiles of the people and to the characteristics of the tasks requiring assistance. The study has laid the groundwork for a reflection requiring further examination in subsequent studies. The developments in the field will thus enable the deployment of intervention modes favouring self-determination by people with ID. This research also questioned the link between certain experimental designs and the action areas that are prioritized in interventions for people with ID. In fact, despite self-determination being at the heart of intervention practises, the research designs and technological guidance modes used to date have left little room for expressing the four essential characteristics of self-determination. This would then help provide a new perspective on the guidance modes proposed to these people.

\section{References}

[1] Ministère de la Santé et des Services sociaux (MSSS). Chez soi : le premier choix, la politique de soutien à domicile. Québec: Author ; 2003.

[2] Morin P, Robert D, Dorvil H. Le logement comme facteur d'intégration sociale pour les personnes classées malades mentales et les personnes classées déficientes intellectuelles. Nouvelles pratiques sociales 2001;14(2):88-105.

[3] Ministère de la Santé et des Services sociaux (MSSS). De l'intégration à la participation 
sociale : Politique de soutien aux personnes présentant une déficience intellectuelle à leurs familles et aux autres proches. Québec: Author ; 2001.

[4] Proulx J, Dumais L, Vaillancourt Y. Le logement à soutien gradué: Évaluation d'un projet prometteur pour les personnes ayant une déficience intellectuelle (No 07-09). Montréal: Laboratoire de recherche sur les pratiques et les politiques sociales (LAREPPS) - Université du Québec à Montréal (UQAM) ; 2007.

[5] Haelewyck M-C, Nader-Grosbois N. L'autorégulation: porte d'entrée vers l'autodétermination des personnes avec retard mental? Revue francophone de la déficience intellectuelle 2004;15(2):173-186.

[6] McConkey R. Variations in the social inclusion of people with intellectual disabilities in supported living schemes and residential setting. Journal of Intellectual Disability Research 2007;51(3):207-217.

[7] Heller T, Miller AB, Factor A. Autonomy in residential facilities and community functioning of adults with mental retardation. Mental Retardation 1999;37:449-457.

[8] Robertson J, Emerson E, Hatton C, Gregory N, Kessissoglou S, Hallam A, Walsh PN. Environmental opportunities and supports for exercising self-determination in communitybased residential settings. Research in Developmental Disabilities 2001;22:487-502.

[9] Stancliffe JR, Abery BH. Longitudinal Study of Deinstitutionalization and the Exercise of Choice. Mental Retardation 1997;35(3):159-169.

[10] Pedlar A, Hutchison P, Arai S. Community Services Landscape in Canada: Survey of Developmental Disability Agencies. Mental Retardation 2000;38(4):330-341.

[11] Lussier-Desrochers D, Lachapelle Y, Caouette M. Challenges in the Completion of Daily Living Activities in Residential Settings. Journal on Developmental Disabilities 2014;20(1):16-24.

[12] Corbeil R, Marcotte A, Trépanier C. Inventaire des habiletés pour la vie en appartement. Québec: Groupe de recherche et d'étude en déficience du développement; 2009.

[13] MacDuff GS, Krantz PJ, McClannahan LE. Prompts and prompt-fading strategies for people with autism. In: Maurice C, Green G, Foxx RM, editors. Making a difference: Behavioral intervention for autism. Texas: Pro-Ed; 2001. p 37-50.

[14] Mechling LC. Assistive Technology as a Self-Management Tool for Prompting Students with Intellectual Disabilities to Initiate and Complete Daily Tasks: A Literature Review. Education and Training in Developmental Disabilities 2007;42[3]:252-269.

[15] Taber-Doughty T, Bouck EC, Tom K, Jasper AD, Flanagan SM, Bassette L. Video Modeling and Prompting: A Comparison of Two Strategies for Teaching Cooking Skills to 
Students with Mild Intellectual Disabilities. Education and Training in Autism and Developmental Disabilities 2011;46(4):499-513.

[16] Taber-Doughty T. Considering student choice when selecting instructional strategies: a comparison of three prompting systems. Research in Developmental Disabilities 2005;26:411-432.

[17] Banda DR, Dogoe MS, Matyszny RM. Review of Video Prompting Studies with Persons with Developmental Disabilities. Education and Training in Autism and Developmental Disabilities 2011;46(4):514-527.

[18] Mechling LC, Gustafson M. Comparison of the Static Picture and Video Prompting on Completion of Cooking Related Tasks by Students with Moderate Intellectual Disabilities. Exceptionality: A Spectial Education Journal 2009;17: 103-116.

[19] Mechling LC, Ayres KM, Purrazzella K, Purrazzella K. Continuous Video Modeling to Prompt Completion of Multi-Component Tasks by Adults with Moderate Intellectual Disability. Education and Training in Autism and Developmental Disabilities 2014;49(1):3-16.

[20] Ayres K, Cihak D. Computer and Video-Based Instruction of Food Preparation Skills: Acquisition, Generalization, and Maintenance. Intellectual and developmental disabilities 2010;48(3):195-208.

[21] Van Laarhoven T, Van Laarhoven-Myers T. Comparaison of three video-based instructional procedures for teaching daily living skills to persons with developmental disabilities. Education and Training in Developmental Disabilities 2006;41(4):365-381.

[22] Lussier-Desrochers D, Lachapelle Y, Pigot H, Beauchet J. Des habitats intelligents pour promouvoir l'autodétermination et l'inclusion sociale. Revue francophone de la déficience intellectuelle 2007;18:3-64.

[23] Dollar CA, Fredirck LD, Alberto PA, Luke JK. Using simultaneous prompting to teach independent living and leisure skills to adults with severe intellectual disabilities. Research in Developmental Disabilities 2012;33:189-195.

[24] Davies DK, Stock SE, Wehmeyer ML. Enhancing Independent Time-Management Skills of Individuals With Mental Retardation Using a Palmtop Personal Computer. Mental Retardation 2002;40(5):358-365.

[25] Cannella-Malone HI, Wheaton JE, Wu PF, Tullis CA, Park JH. Comparing the Effects of Video Prompting with and without Error Correction on Skill Acquisition for Students with Intellectual Disability. Education and Training in Autism and Developmental Disabilities 
2012;47(3):332-344.

[26] Cannella-Malone HI, Brooks DG, Tullis CA. Using Self-Directed Video Prompting to Teach Students with Intellectual Disabilities. Journal of Behavioral Education 2013;22:169-189.

[27] Lachapelle Y, Lussier-Desrochers D, Caouette M, Therrien-Bélec M. Évaluation des impacts d'une technologie mobile d'assistance à la réalisation de tâches sur l'autodétermination des personnes présentant une déficience intellectuelle. Rapport de recherche adressé à l'Office des personnes handicapées du Québec (2361-09-49). TroisRivières (Qc): Université du Québec à Trois-Rivières; 2011.

[28] Lancioni GE, O’Reilly MF, Seedhouse P, Furniss F, Cunha B. Promoting independent task performance by persons with severe developmental disabilities through a new computer-aided system. Behavior Modification 2000;24:700-718.

[29] Lancioni GE, O'Reilly MF, Van den Hof E, Funiss F, Seedhouse P, Rocha N. Task instructions for persons with severe intellectual disability : reducing the number of instruction occasions after the acquisition phase. Behavioral Interventions 1999;14:199-211.

[30] Riffel LA, Wehmeyer ML, Turnbull AP, Davies D, Stock S, Fisher S. Promoting independent performance of transition-related tasks using a palmtop PC-based self-directed visual and auditory prompting system. Journal of Special Education Technology 2005;20:5-14.

[31] Sabielny LM, Cannella-Malone HI. Comparison of Prompting Strategies on the Acquisition of Daily Living Skills. Education and Training in Autism and Developmental Disabilities 2014;49(1):145-152.

[32] Lancioni GE, van den Hof E, Boelens H, Rocha N, Seedhouse P. A Computer-Based System Providing Pictorial Instructions and Prompts to Promote Task Performance in Persons with Severe Developmental Disabilities. Behavioral Interventions 1998;13:111-122.

[33] Cannella-Malone H, Sigafoos J, O'Reilly M, de la Cruz B, Edrisinha C, Lancioni GE. Comparing Video Prompting to Video Modeling for Teaching Daily Living Skills to Six Adults with Developmental Disabilities. Education and Training in Developmetal Disabilities 2006;41(4):344-356.

[34] Lussier-Desrochers D, Lachapelle Y, Pigot H, Beauchet J. Des habitats intelligents pour promouvoir l'autodétermination et l'inclusion sociale. Revue francophone de la déficience intellectuelle 2007;18:53-64.

[35] Scott R, Collins B, Knight V, Kleinert H. Teaching Adults with Moderate Intellectual Disability ATM Use via the iPod. Education and Training in Autism and Developmental Disabilities 2013;48(2):190-199. 
[36] Mechling LC, Seid NH. Use of a Hand-Held Personal Digital Assistant (PDA) to SelfPrompt Pedestrian Travel by Young Adults with Moderate Intellectual Disabilities. Education and Training in Autism and Developmental Disabilities 2011;46(2):220-237.

[37] Davies DK, Stock SE, Wehmeyer ML. A Palmtop computer-based intelligent aid for individuals with intellectual disabilities to increase independent decision making. Research and Practice for Persons with Severe Disabilities 2003;28:182-193.

[38] Davies DK, Stock SE, Wehmeyer ML. Enhancing independent task performance for individuals with mental retardation through use of a handheld self-directed visual and audio prompting system. Education and Training in Mental Retardation and Developmental Disabilities 2002;37:209-218.

[39] Furniss F, Ward A, Lancioni G, Rocha N, Cunha B, Seedhouse P, et al. A palmtop-based job aid for workers with severe intellectual disabilities. Technology and Disability 1999;10:53-67.

[40] Wennberg B, Kjellberg A. Participation When Using Cognitive Assistive Devices - from the Perspective of People with Intellectual Disabilities. Occupational Therapy International 2010;17:168-176.

[41] Davies DK, Stock SE, Wehmeyer M. Application of Computer Simulation to Teach ATM Access to Individuals with Intellectual Disabilities. Education and Training in Developmental Disabilities 2003;38(4):451-456.

[42] Mechling LC, Gast DL, Seid NH. Evaluation of a Personal Digital Assistant as a SelfPrompting Device for Increasing Multi-Step Task Completion by Students with Moderate Intellectual Disabilities. Education and Training in Autism and Developmental Disabilities 2010;45(3):422-439.

[43] van Laarhoven T, van Laarhoven-Myers T. Comparison of Three Video-based Instructional Procedures for Teaching Daily Living Skills to Persons with developmental Disabilities. Education and Training in developmental Disabilities 2006;41(4):365-381.

[44] Sigafoos J, O’Reilly M, Cannella H, Upadhyaya L, Edrinsinha C, Lancioni GE, Young D. Computer-Presented Video Prompting for Teaching Microwave Oven Use to Three Adults with Developmental Disabilities. Journal of Behavioral Education 2005;14(3):189-201.

[45] Alario F-X, Ferrand L. A set of 400 pictures standardized for French: norms for name agreement, image agreement, familiarity, visual complexity, image variability, and age of acquisition. Behavior Research Methods, Instruments, \& Computers 1999;31:531-552.

[46] Caouette M. Étude descriptive des pratiques d'intervention en CRDITED favorisant l'autodétermination d'adultes présentant une déficience intellectuelle : la perspective des intervenants (Thèse de doctorat inédite). Trois-Rivières (QC): Université du Québec à Trois-Rivières; 2014. 303 p. 
[47] Lachapelle Y, Lussier-Desrochers D, Caouette M, Therrien-Bélec M. L'utilisation d'un assistant au déplacement : Étude de cas en déficience intellectuelle. Revue Francophone de la déficience intellectuelle 2011;22:63-68.

[48] Dixon RA, Garrett DD, Bäckman L. Principles of compensation in cognitive neuroscience and neurorehabilitation. In: Stuss DT, Winocur G, Robertson IH, editors. Cognitive neurorehabilitation (2nd ed.). Cambridge: Cambridge University Press; 2008. p 22-38.

[49] Lussier-Desrochers D, Caouette M. Technologies de soutien à l'intervention : une visée d'apprentissage ou de suppléance ? Revue du Consortium national de recherche sur l'intégration sociale (CNRIS) 2013;4(3):23.

[50] Carrier S. Une nouvelle définition de l'intervention d'adaptation en sites réguliers. Revue francophone de la déficience intellectuelle (RFDI). Actes du Colloque Recherche Défi 2002, Numéro spécial - Mai 2002. p. 81-83.

[51] Sauzéon H, Lestage P, Raboutet C, N'Kaoua B, Claverie B. Verbal fluency output in children aged 7-16 as a function of the production criterion: Qualitative analysis of clustering, switching processes, and semantic network exploitation. Brain and Language 2004;89:192-202.

[52] Rowe J, Lavender A, Turk V. Cognitive executive function in Down's syndrome. British Journal of Clinical Psychology 2006;45:5-17.

[53] Nash HM, Snowling MJ. Semantic and phonological fluency in children with Down syndrome: Atypical organization of language or less efficient retrieval strategies? Cognitive Neuropsychology 2008;25(5):690-703.

[54] Rondal JA. Exceptional language development in Down syndrome: Implications for the cognition-language relationship. New York: Cambridge University Press; 1995.

[55] Lott T, Dierssen M. Cognitive deficits and associated neurological complications in individuals with Down's syndrome. The Lancet Neurology 2010;9:623-33.

[56] Willner P, Bailey R, Parry R, Dymond S. Performance in Temporal Discounting Tasks by People With Intellectual Disabilities Reveals Difficulties in Decision-Making and Impulse Control. American Journal on Intellectual and Developmental Disabilities 2010;115(2):157-171.

[57] Wehmeyer ML, Kelchner K, Richards S. Essential Characteristics of Self Determined Behavior of Individuals With Mental Retardation. American Journal on Mental Retardation 1996;100(6):632-642. 
[58] Geusgens CA, Winkens I, van Heugten CM, Jolles J, van den Heuvel WJ. Occurrence and measurement of transfer in cognitive rehabilitation: A critical review. Journal of Rehabilitation Medicine 2007;39:425-439.

[59] Toglia J, Johnston MV, Goverover Y, Dain B. A multicontext approach to promoting transfer of strategy use and self regulation after brain injury: An exploratory study. Brain Injury 2010;24:664-677.

[60] Rizzo AA, Schultheis M, Kerns KA, Mateer C. Analysis of assets for virtual reality applications in neuropsychology. Neuropsychology Rehabilitation 2004;14:207-239. 


\section{Table 1}

Summary of the organization strategies used by the participants with ID when navigating in the application and when performing an action, according to the type of tasks requested $(n=5)$

\begin{tabular}{lccc}
\hline Participant (Age) & Picnic Meal & Picnic Activity & Securing \\
\hline No. 1 (23 years) & (Categorical) & (Unspecified) & Visual \\
No. 3 (24 years) & $\begin{array}{c}\text { (Unspecified) } \\
\text { Unspecified }\end{array}$ & $\begin{array}{c}\text { (Unspecified) } \\
\text { Visual }\end{array}$ & Visual \\
No. 5 (25 years) & Action-directed & Visual & Action-directed \\
No. 7 (26 years) & (Categorical) & (Visual) & Visual \\
No. 9 (31 years) & (Schematic) & (Unspecified) & (Visual) \\
\hline
\end{tabular}


Table 2

Summary of the organization strategies used by the participants in the control group, according to the type of tasks requested $(n=5)$

\begin{tabular}{lccc}
\hline Participant (Age) & Picnic Meal & Picnic Activity & Securing \\
\hline No. 2 (23 years $)$ & Visual & Visual & Visual \\
No. $4(24$ years $)$ & Visual & Visual & Action-directed \\
No. $6(25$ years $)$ & Visual & Visual & Action-directed \\
No. $8(26$ years $)$ & Visual & Visual & Visual \\
No. $10(31$ years $)$ & Visual & Visual & Action-directed \\
\hline
\end{tabular}




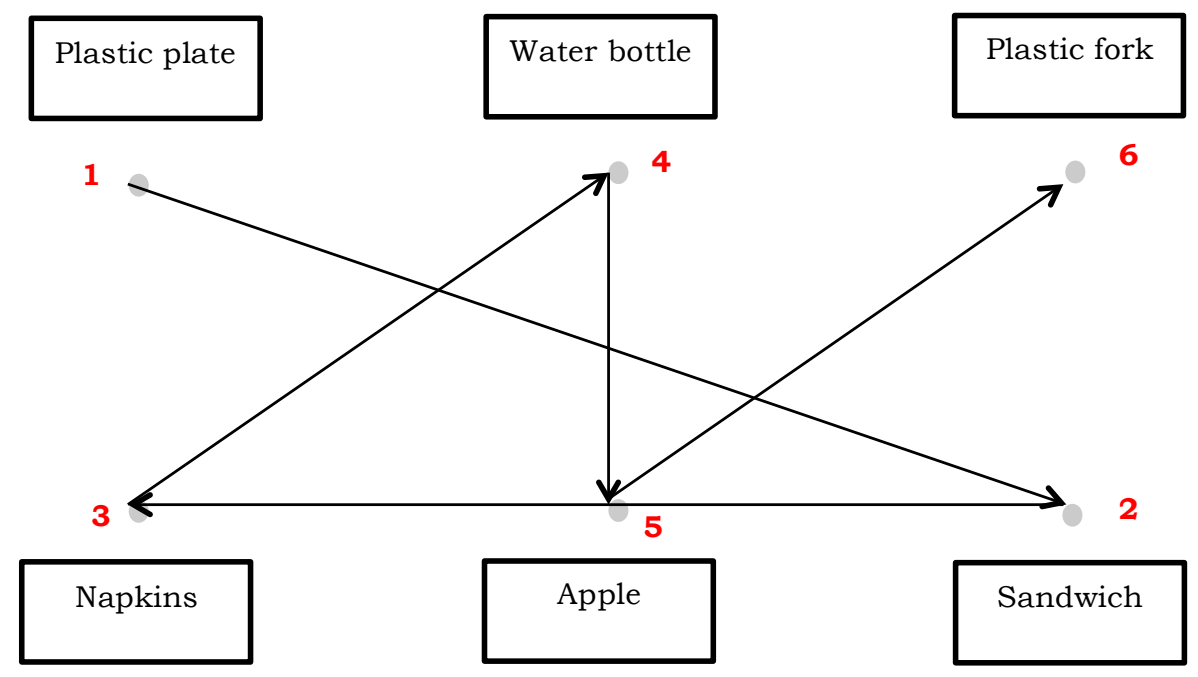

Figure 1. Map of the organization method used by Participant No. 9 when interacting with the application with respect to the picnic meal. 


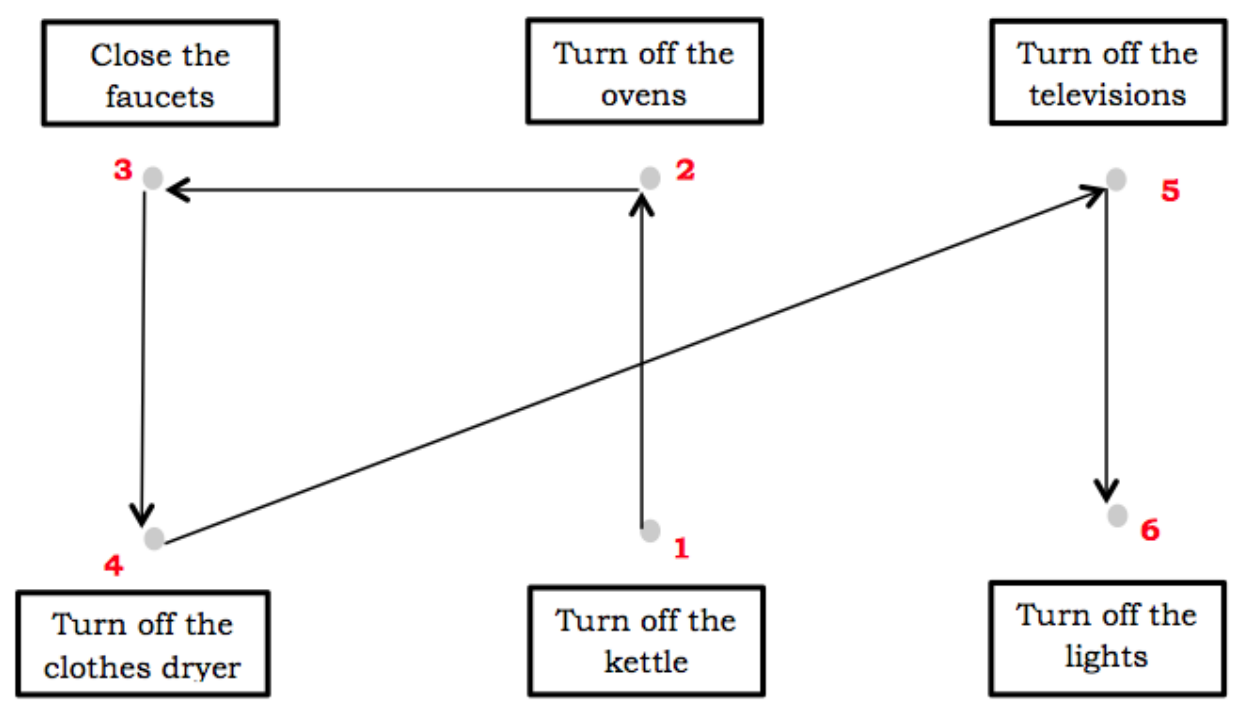

Figure 2. Map of the organization method used by Participant No. 5 when interacting with the application with respect to the securing task. 